\title{
SCIENTIFIC REPORTS

\section{OPEN Associations between self-reported sleep characteristics and incident mild cognitive impairment: The Heinz Nixdorf Recall Cohort Study}

\author{
Christian Brachem (iD ${ }^{1}$, Angela Winkler ${ }^{2}$, Sarah Tebrügge ${ }^{2}$, Christian Weimar ${ }^{2}$, Raimund Erbel ${ }^{3}$, \\ Karl-Heinz Jöckel ${ }^{3}$, Andreas Stang ${ }^{4,5}$, Nico Dragano ${ }^{6}$, Susanne Moebus ${ }^{3}$, Bernd Kowall ${ }^{4,7 *}$ \& \\ Martha Jokisch ${ }^{2,7}$
}

Associations of sleep characteristics with mild cognitive impairment (MCI) have been examined in cross-sectional, but rarely in longitudinal studies. Incident $\mathrm{MCl}$ and sleep characteristics were assessed in 1,890 participants of the first and second follow-up of the Heinz Nixdorf Recall study, a populationbased cohort study in Germany (age at first follow-up 50-80 years, mean follow-up 5.2 years). MCI was assessed with extensive cognitive tests. Sleep questionnaires including PSOI (Pittsburgh Sleep Quality Index) were used to assess sleep quality, sleep disturbances, time asleep, and time in bed. Relative risks (RR) of developing $\mathrm{MCl}$ when exposed to sleep characteristics were assessed in regression models adjusted for sociodemographic and cardiovascular risk factors. Poor sleep quality (PSOI $>5)(R R=1.43$, $95 \% \mathrm{Cl}: 1.12-1.82$, fully adjusted, reference: $\mathrm{PSOI} \leq 5$ ) and difficulties initiating sleep (almost nightly versus never) $(R R=1.40,0.94-2.08)$ were associated with incident $\mathrm{MCl}$. For time in bed, the risk of $\mathrm{MCl}$ was increased for $\leq 5$ hours ( $R R=2.86,1.24-6.60$, reference: 7 to $<8$ hours). In this longitudinal study with older participants, $\mathrm{MCl}$ risk was increased in persons with poor sleep quality, difficulties initiating sleep, and short time in bed.

Dementia is a growing public health burden worldwide. In 2013 an estimated 44.35 million persons had a prevalent dementia ${ }^{1}$. By 2050 it is expected that this number triples to 135.46 million prevalent dementia cases ${ }^{2,3}$. Because no effective causal medical therapies are available for dementia, primary prevention of dementia and of its early precursors is the most promising option currently available to cap the rising prevalence ${ }^{4,5}$.

Subjects with mild cognitive impairment (MCI) have an increased risk of progression to Alzheimer's disease (AD) and other forms of dementia. Therefore, identification of modifiable risk factors for incident MCI is important, and poor sleep is considered a potential risk factor for cognitive decline and disease progression ${ }^{6-13}$.

Sleep characteristics were suggested as modifiable risk factors for cognitive decline, for example by influencing hippocampal volume ${ }^{14,15}$. Two up-to-date reviews on this relationship indicate an association between cognitive decline and sleep problems, such as poor sleep quality, short or long sleep duration, and sleep disturbances ${ }^{12,16}$. However, both reviews concluded that there is still a need for long term prospective studies to ensure that sleep problems precede cognitive decline ${ }^{12,16}$. Two recently published cohort studies on sleep characteristics and dementia were not included in these reviews ${ }^{17,18}$. Both suggest that self-reported long sleep duration as well as self-reported sleep disturbances increase the risk of dementia. Additionally, Jackowska and Cadar ${ }^{19}$ found an association between decreased cognitive function and self-reported long and short sleep duration in their

${ }^{1}$ Nutritional Epidemiology, Department of Nutrition and Food Science, Rheinische Friedrich-Wilhelms-University Bonn, Bonn, Germany. ${ }^{2}$ Department of Neurology, University Hospital of Essen, University of Duisburg-Essen, Essen, Germany. ${ }^{3}$ Institute for Medical Informatics, Biometry and Epidemiology, University Hospital Essen, University Duisburg-Essen, Essen, Germany. ${ }^{4}$ Center of Clinical Epidemiology, Institute for Medical Informatics, Biometry and Epidemiology, Medical Faculty, University Duisburg-Essen, Essen, Germany. ${ }^{5}$ School of Public Health, Department of Epidemiology Boston University, 715 Albany Street, Talbot Building, Boston, MA, 02118, USA. ${ }^{6}$ Institute of Medical Sociology, Medical Faculty, University of Duesseldorf, Duesseldorf, Germany. ${ }^{7}$ These authors jointly supervised to this work: Bernd Kowall and Martha Jokisch. *email: bernd.kowall@uk-essen.de 
prospective cohort study. However, there is still a knowledge gap for longitudinal studies on sleep characteristics and mild cognitive impairment.

Using longitudinal data of the Heinz Nixdorf Recall Study (HNR Study), this study aims to fill this knowledge gap and to extend a previous cross-sectional analysis of HNR Study data ${ }^{11}$. To this purpose, we examined the relationship between multiple sleep exposures (overall sleep quality; difficulties maintaining or initiating sleep, early-morning awakening; time in bed, time asleep (i.e. sleep duration without time awake in bed) and total sleep duration) and incidence of MCI.

\section{Methods}

Participants. The HNR Study is a population-based prospective cohort study conducted in three large adjacent cities (Bochum, Essen, Mülheim) in the Ruhr-region of North-Rhine-Westphalia, Germany. The study rationale and design have been described in detail elsewhere ${ }^{20,21}$. In short, the cohort comprises a total of 4,814 participants (49.8\% men, aged 45-75 years). The baseline visits ( $\mathrm{t} 0$ ) were performed between 2000 and 2003 . The median follow-up time was 5.1 years for the 5-year follow-up visits between 2005 and 2008 (t1), and 5.2 years for the 5-year follow-up visits between 2010 and 2015 (t2). Data assessment at baseline and at follow-up visits included a self-administered questionnaire, face-to-face interviews, and a physical examination including among others anthropometric measurements and comprehensive laboratory tests. Permission to conduct this study was granted by the Institutional Review Board (IRB) of the Medical Faculty of the University of Duisburg-Essen (Approval Number: 99-69-1200). The study was performed in accordance with the approved guidelines and regulations. All participants gave their written informed consent.

In the HNR Study, cognitive tests were performed at the second $(\mathrm{t} 1)$ and the third visit $(\mathrm{t} 2)$ at the study centre. Participants with a diagnosis of dementia by a physician or taking cholinesterase inhibitors (anatomic-therapeutic-chemical classification issued by the World Health Organization (ATC) code: N06DA)) or other anti-dementia drugs (ATC: N06DX) or fulfilling the DSM-IV dementia diagnosis at t1, were excluded from the regression analysis. As our outcome of interest was incident $\mathrm{MCI}$ at $\mathrm{t} 2$, participants with $\mathrm{MCI}$ at $\mathrm{t} 1$ were excluded as well. Participants were included into the present study if data were available for all variables of interest for the complete case analysis (Fig. $1 ; \mathrm{n}=1890$ ).

Cognitive assessment. The cognitive performance at $\mathrm{t} 2$ was measured using eight neuropsychological subtests: (1) immediate and (2) delayed recall of eight words (performance measured as number of words recalled in each trial) ${ }^{22}$, (3) labyrinth test (time in seconds needed to find the way out of a maze $)^{22}$, (4) verbal fluency "animals" (number of words named within one minute) ${ }^{23},(5)$ clock-drawing test (performance was rated from 1 (perfect clock) to 6 (poor performance) $)^{24},(6,7)$ Trail Making Test A and B (A: time in seconds needed to connect a series of consecutively numbered circles; $B$ : time in seconds needed to connect a series of numbered and lettered circles in alternating sequence) $)^{25}$, (8) colour-word test ${ }^{22}$ (time in seconds needed to read written colour words inked in black (card 1), time in seconds needed to name coloured bars (card 2), time in second needed to name the colour of written colour words, when the written word and printed ink was not congruent (card 3) and difference card 3 - card 2 as interference performance). Tests were grouped into four domains (see Table 1). The first five subtests had already been performed at $\mathrm{t} 1$. For a detailed description of tests (1) to (5) see Wege et al. $(2011)^{26}$ and of tests (6) to (8) see Tebrügge et al. $(2018)^{27}$. For the five subtests that have already been performed at $\mathrm{t} 1$, we performed $\mathrm{z}$-transformation of the raw data at $\mathrm{t} 2$ using our own defined norm-data from $\mathrm{t} 1$ : raw data were $\mathrm{z}$-transformed based on the mean and standard deviation (SD) of the appropriate age- and education group at $t 1$ (age: 50 to 59 years, 60 to 69 years, and $\geq 70$ years; education: $\leq 10$ years, 11 to 13 years, and $\geq 14$ years) ${ }^{28}$. For the three subtests that were additionally conducted at $\mathrm{t} 2$, $\mathrm{z}$-transformation was based on the same education groups and the following three age groups from t2: 55 to 64 years, 65 to 74 years and $\geq 75$ years ${ }^{28}$. Except for the clock-drawing test, the age- and education-adjusted test scores were scaled to have a mean of 10 and a SD of $3^{28}$. Within each domain (attention, executive function, verbal memory and visuoconstruction), newly scaled scores of the tests were added. To account for the differing numbers of tests in each domain, domain scores were then scaled to have a mean of 10 and a SD of $3^{28}$. Cognitive impairment was defined as a performance of more than one SD below the mean $(\leq 7)$ in at least one total domain score of the domains attention, executive function, verbal memory, or as a score of $\geq 3$ in visuoconstruction ${ }^{28}$.

Definition of mild cognitive impairment. The MCI diagnosis at $\mathrm{t} 2 \mathrm{was}$ based on the following published MCI criteria ${ }^{29,30}$ : (1) cognitive impairment in at least one of the above reported four domains; (2) subjective cognitive decline over the past two years; (3) generally intact activities of daily living; (4) no dementia diagno$\mathrm{sis}^{28}$. To examine incident MCI, participants with MCI at $\mathrm{t} 1$ were excluded. Because cognitive assessment at $\mathrm{t} 1$ consisted of only five subtests, we were unable to build cognitive domain scores at this time-point. Thus, the first MCI criterion (cognitive impairment) was met if the participant performed more than one SD below the age and education-adjusted mean in at least one subtest or had a score of $\geq 3$ in the clock-drawing test. Participants at $\mathrm{t} 2$ not meeting MCI criteria as described above were categorized as 'no $\mathrm{MCI}^{28}$.

Assessment of sleep characteristics. Sleep variables were assessed in a computer-assisted interview. In addition to the Pittsburgh Sleep Quality Index (PSQI) ${ }^{31}$, we asked six questions, three on sleep disturbances, and three on sleep duration.

Sleep quality: PSQI. The PSQI is a standardised, self-rated questionnaire that measures sleep quality. The questionnaire consists of seven sub-scores that are described in detail elsewhere ${ }^{31}$. Poor overall sleep quality is indicated by a PSQI score of $>5^{31}$, and accordingly, PSQI was grouped to scores of $\leq 5$ and $>5$ in the regression analyses. 


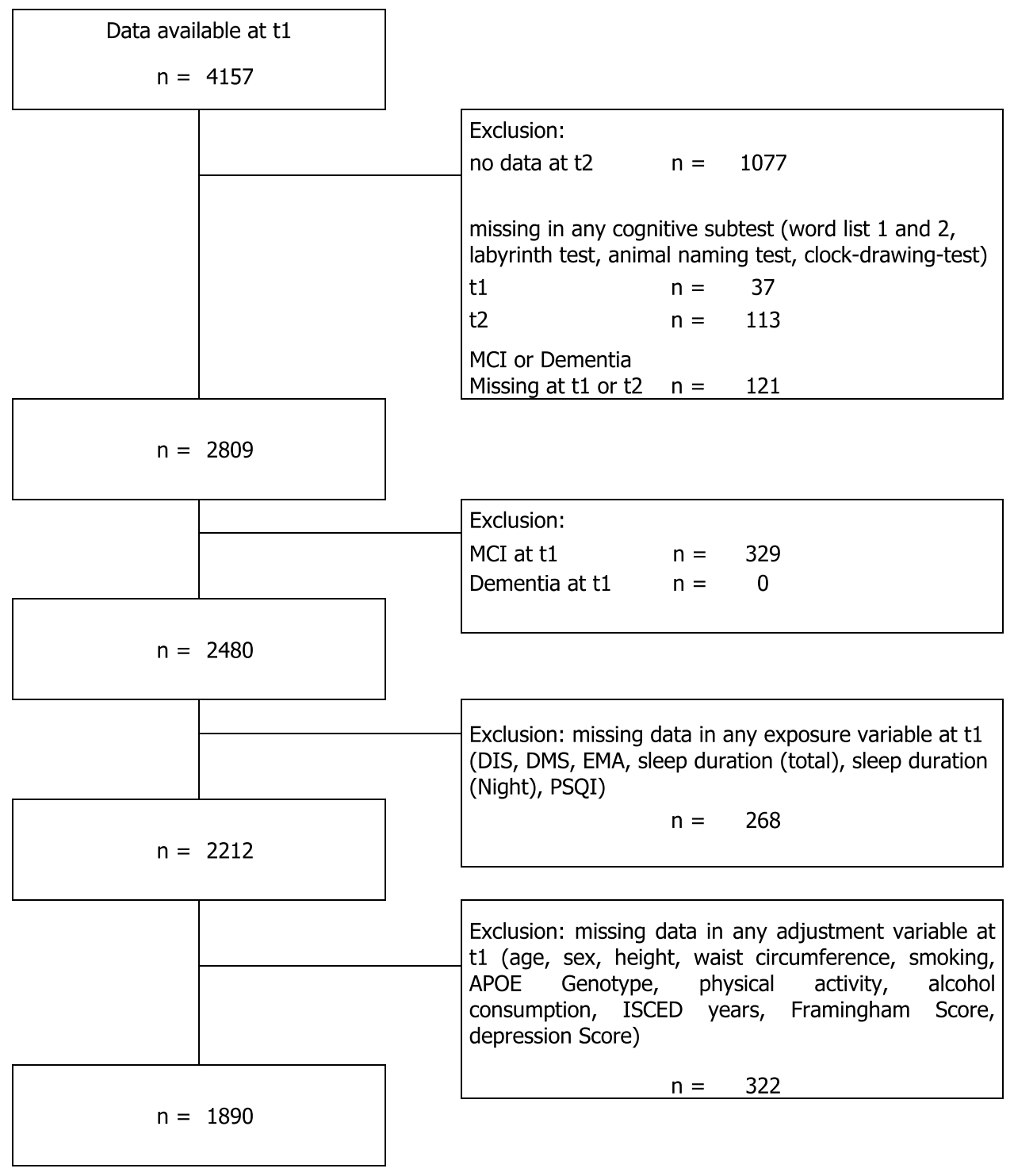

Figure 1. Flow-chart of persons entering the complete case analysis dataset. Abbreviations: MCI - Mild Cognitive Impairment; Cont. - Continuous Cognition Variables; DIS - Difficulties Initiating Sleep; DMS Difficulties Maintaining Sleep; EMA - Early-morning Awakening; PSQI - Pittsburg Sleep Quality Index; ISCED - International Standard Classification of Education.

\begin{tabular}{|l|l|}
\hline Cognitive Domain & Tests \\
\hline Attention & $\begin{array}{l}\text { Trail Making Test A, Color-word test card } \\
1 \text { and card 2 }\end{array}$ \\
\hline Executive Function & $\begin{array}{l}\text { Trail Making Test B, Labyrinth test, Color- } \\
\text { word test interference performance (card } \\
3-\text { card 2) }\end{array}$ \\
\hline Verbal Memory & $\begin{array}{l}\text { Eight-word list immediate and delayed } \\
\text { recall }\end{array}$ \\
\hline Visuoconstruction & Clock-drawing test \\
\hline
\end{tabular}

Table 1. Description of cognitive domains.

Sleep disturbances. The additional questions about sleep disturbances were: "Have you experienced difficulties initiating sleep during the past four weeks?", "Have you experienced difficulties maintaining sleep during the past four weeks?" and "Have you experienced early-morning awakening during the past four weeks?" Each question had the following answer possibilities: never (during the past four weeks), sometimes (once or less than once a week), often (at least twice a week), and almost every night (at least five nights a week). The reference category for regression analysis was "never (during the past four weeks)". 
Nocturnal sleep duration. We used the two following variables to assess self-reported nocturnal sleep duration:

1. "Time asleep" (i.e., sleep duration without time awake in bed) which is assessed using an item from the PSQI ("During the past month, how many hours of actual sleep did you get at night? This may be different than the number of hours you spend in bed.").

2. "Time in bed" was calculated from two items in the PSQI ("During the past month, when have you usually gone to bed?", "During the past month, when have you usually got up in the morning?").

Duration of napping and total sleep duration. In addition, we asked two questions on frequency and duration of napping ("How frequently do you usually nap?", and "How many hours do you usually nap?" assessed as hours and minutes). The question about nap frequency had the following choices: never, less than once a week, one to four times per week, five to six times per week, and daily. Mean duration of daytime napping was calculated as reported duration of daytime napping multiplied by its relative frequency. Total sleep duration was calculated as the sum of time in bed during the night plus duration of daytime napping.

Time asleep, time in bed, and total sleep duration were categorised according to the American National Sleep Foundation's recommendations ${ }^{32}$ into: $\leq 5$ hours, $>5$ to $<7$ hours, 7 to $<8$ hours (reference), 8 to $<9$ hours and $\geq$ 9 hours. Sleep duration was categorised because of the hypothesized non-linear dependency and the tendency of participants to answer in half-hour intervals.

Covariates. As part of the first follow-up visit of the HNR Study at $\mathrm{t} 1$, information about medical and family history, cardiovascular risk factors, lifestyle and various sociodemographic factors were assessed in a computer assisted interview ${ }^{20,21}$. The variables used for model adjustment were selected based on a directed acyclic graph (DAG) based on current literature on the topic. The DAG (appendix 1) was constructed using the online software DAGity v2.3 ${ }^{33}$. The minimally sufficient adjustment set was: age, sex, height, waist circumference, cardio-vascular disease (CVD) risk, physical activity, smoking status, International Standard Classification of Education (ISCED) years, pure alcohol consumption, Apolipoprotein E (APOE) $\varepsilon 4$ genotype, and depression score. Age (in years), sex (male, female), height $(\mathrm{cm})$, waist circumference $(\mathrm{cm})$, CVD risk (as Framingham Risk Score), physical activity (as Metabolic Equivalent of Tasks - hours (MET-h)/week), ISCED years, pure alcohol consumption (grams/ week), and depression score (short form of the Center for Epidemiologic Studies Depression Scale, German ver$\operatorname{sion}^{34}$ ) were used as continuous variables. Smoking status (current, former, never (reference)) and APOE $\varepsilon 4$ genotype ( $\varepsilon 4$ carrier: at least one $\varepsilon 4$ allele $(\varepsilon 2 / \varepsilon 4, \varepsilon 3 / \varepsilon 4, \varepsilon 4 / \varepsilon 4)$, non-carrier(reference)) were used as categorical variables. Further details on the covariate assessment have been described elsewhere ${ }^{21,26}$. We did not categorise the continuous variables used in the adjustment set.

Statistical analysis. We used a log-linear model with a Poisson working likelihood and robust standard errors to obtain relative risks and corresponding $95 \%$ confidence intervals ${ }^{35,36}$. The outcome variable was incident MCI, exposure variables were global sleep quality assessed by the PSQI score, sleep disturbances, time asleep, time in bed, and total sleep duration.

For each exposure of interest, we calculated three models: first, a crude model (cf. appendix 5) with only the exposure as an independent variable; second, a model additionally adjusted for age and sex (cf. appendix 5); third, a fully adjusted model including all variables suggested by the DAG.

We performed regression analyses with complete case analyses $(\mathrm{N}=1890)$, and, in addition, with multiple imputations $(\mathrm{N}=2480)$ (cf. Fig. 1). Missing data was imputed with PROC MI in SAS 9.4. All variables in the fully adjusted regression model were used in the imputation model $\left(\mathrm{n}_{\text {impute }}=10\right)$. A table detailing patterns of missing in all variables used in the imputation can be found in the supplementary material (cf. appendix 2-4). The overall fraction of missing data was $2.4 \%$. This ranged from no missing data (e.g. in age and sex) to $10.6 \%$ in the PSQI score.

All statistical analysis was performed using SAS 9.4. We calculated estimates and corresponding 95\% confidence intervals to assess the precision of our estimates because estimation, not significance testing, was our goal. Further, we wished to avoid publication bias by preferential reporting of statistically significant results. Instead, we judged our estimates by their precision and validity.

Additional analyses. We used changes of sleep duration between T1 and T0 as a further exposure of interest. Changes of sleep duration (sleep duration at T1 minus sleep duration at baseline) were grouped into three categories ( $\leq-1$ hour, -1 hour to 1 hour (reference), $\geq 1$ hour). As the PSQI was not administered to participants at baseline, we used another item for calculation of change of sleep duration between T1 and T0: Participants were asked "How many hours do you sleep per night on average?", and they were instructed to indicate hours and minutes in a computer assisted interview. Additionally, we stratified our cohort into three age groups (45 to 54,55 to 64 and 65 to 74 years) to look for effect modification by age. Furthermore, we stratified our cohort by APOE carrier status to investigate effect modification. For these additional analyses, we used the same modelling procedures and adjustment sets as described above.

\section{Results}

Social and clinical characteristics. The sociodemographic and clinical characteristics of all 1890 participants included in the complete case analysis are presented in Table 2. Participants with short time asleep ( $\leq 5$ hours) were more often women and had higher proportions of sleep disturbances and poor sleep quality (PSQI $>5$ ). These participants had more difficulties maintaining sleep, more difficulties initiating sleep, and more 


\begin{tabular}{|c|c|c|c|c|c|c|}
\hline \multirow[b]{2}{*}{ Variable } & & \multicolumn{5}{|l|}{ Time asleep } \\
\hline & & $\leq 5 h$ & $>5 h$ to $<7 h$ & $7 \mathrm{~h}$ to $<8 \mathrm{~h}$ & $8 h$ to $<9 h$ & $\geq 9 \mathrm{~h}$ \\
\hline $\mathrm{N}$ & & $209(100.0 \%)$ & $612(100.0 \%)$ & $655(100.0 \%)$ & $352(100.0 \%)$ & $62(100.0 \%)$ \\
\hline Sex & Female & $138(66.0 \%)$ & $311(50.8 \%)$ & $336(51.3 \%)$ & $162(46.0 \%)$ & $26(41.9 \%)$ \\
\hline Age (years) & & $57.5 \pm 7.2$ & $56.7 \pm 7.0$ & $57.9 \pm 7.0$ & $60.2 \pm 7.1$ & $60.8 \pm 6.1$ \\
\hline \multirow{2}{*}{ Sleep Quality: PSQI Score ${ }^{\mathrm{a}}$} & & $11.0 \pm 3.4$ & $6.6 \pm 2.9$ & $4.0 \pm 2.1$ & $3.4 \pm 1.9$ & $3.2 \pm 1.9$ \\
\hline & $>5$ & $197(94.3 \%)$ & $369(60.3 \%)$ & $134(20.5 \%)$ & $40(11.4 \%)$ & $7(11.3 \%)$ \\
\hline \multirow{3}{*}{ Difficulties Initiating Sleep } & Sometimes & $45(21.5 \%)$ & $231(37.7 \%)$ & $262(40.0 \%)$ & $130(36.9 \%)$ & $21(33.9 \%)$ \\
\hline & Often & $64(30.6 \%)$ & $125(20.4 \%)$ & $93(14.2 \%)$ & $28(8.0 \%)$ & $6(9.7 \%)$ \\
\hline & Almost every Night & $66(31.6 \%)$ & $43(7.0 \%)$ & $19(2.9 \%)$ & $8(2.3 \%)$ & $2(3.2 \%)$ \\
\hline \multirow{3}{*}{ Difficulties Maintaining Sleep } & Sometimes & $19(9.1 \%)$ & $142(23.2 \%)$ & $177(27.0 \%)$ & $114(32.4 \%)$ & $14(22.6 \%)$ \\
\hline & Often & $60(28.7 \%)$ & $164(26.8 \%)$ & $180(27.5 \%)$ & $92(26.1 \%)$ & $12(19.4 \%)$ \\
\hline & Almost every Night & $124(59.3 \%)$ & $255(41.7 \%)$ & $209(31.9 \%)$ & $104(29.5 \%)$ & $29(46.8 \%)$ \\
\hline \multirow{3}{*}{ Early-morning Awakening } & Sometimes & $45(21.5 \%)$ & $187(30.6 \%)$ & $227(34.7 \%)$ & $117(33.2 \%)$ & $19(30.6 \%)$ \\
\hline & Often & $62(29.7 \%)$ & $144(23.5 \%)$ & $98(15.0 \%)$ & $44(12.5 \%)$ & $1(1.6 \%)$ \\
\hline & Almost every Night & $62(29.7 \%)$ & $76(12.4 \%)$ & $25(3.8 \%)$ & $10(2.8 \%)$ & $3(4.8 \%)$ \\
\hline APOE $\varepsilon 4$ Genotype & $\varepsilon 4$ Carrier $^{\mathrm{b}}$ & $42(20.1 \%)$ & $152(24.8 \%)$ & $173(26.4 \%)$ & $85(24.1 \%)$ & $15(24.2 \%)$ \\
\hline Alcohol Consumption [g/week] & $9.77 \pm 17.39$ & $9.8 \pm 17.4$ & $8.1 \pm 13.8$ & $8.9 \pm 15.4$ & $9.4 \pm 16.2$ & \\
\hline Depression Score ${ }^{\mathrm{c}}$ & & $9.1 \pm 5.9$ & $7.7 \pm 5.9$ & $6.7 \pm 5.4$ & $6.6 \pm 5.4$ & $6.5 \pm 6.2$ \\
\hline Framingham Risk Score & & $0.2 \pm 0.2$ & $0.2 \pm 0.2$ & $0.2 \pm 0.2$ & $0.3 \pm 0.2$ & $0.3 \pm 0.2$ \\
\hline Height $[\mathrm{cm}]$ & & $167.1 \pm 9.4$ & $169.4 \pm 9.0$ & $169.5 \pm 9.3$ & $169.5 \pm 9.1$ & $170.9 \pm 9.0$ \\
\hline ISCED [years] & & $13.9 \pm 2.1$ & $14.5 \pm 2.4$ & $14.5 \pm 2.4$ & $14.3 \pm 2.3$ & $13.8 \pm 2.1$ \\
\hline $\begin{array}{l}\text { Physical Activity [MET-h/ } \\
\text { Week] }\end{array}$ & $40.64 \pm 44.81$ & $40.6 \pm 44.8$ & $42.1 \pm 39.3$ & $45.6 \pm 42.2$ & $52.4 \pm 55.2$ & \\
\hline Waist Circumference $[\mathrm{cm}]$ & & $92.3 \pm 14.6$ & $91.9 \pm 12.8$ & $92.4 \pm 12.4$ & $93.4 \pm 12.3$ & $95.7 \pm 14.3$ \\
\hline \multirow{2}{*}{ Smoking Status } & Former Smoker & $75(35.9 \%)$ & $240(39.2 \%)$ & $239(36.5 \%)$ & $128(36.4 \%)$ & $23(37.1 \%)$ \\
\hline & Current Smoker & $42(20.1 \%)$ & $126(20.6 \%)$ & $110(16.8 \%)$ & $83(23.6 \%)$ & $13(21.0 \%)$ \\
\hline
\end{tabular}

Table 2. Baseline characteristics stratified by nocturnal sleep duration: the Heinz Nixdorf Recall Study. All numbers were derived from the complete case analysis dataset $(\mathrm{N}=1890)$. Data is displayed as $\mathrm{N}$ (Col Percent) or Mean \pm Standard Deviation. Reference Categories were omitted. Abbreviations: PSQI: Pittsburgh Sleep Quality Index; g: Gramm; cm: Centimetres; ISCED: International Standard Classification of Education; METh: Metabolic Equivalent of Task - hours, APOE. Apolipoprotein E. a Score $>5$ indicates poor sleep quality ${ }^{\mathrm{b}} \varepsilon 4$ carrier: at least one 4 allele $(\varepsilon 2 / \varepsilon 4, \varepsilon 3 / \varepsilon 4, \varepsilon 4 / \varepsilon 4){ }^{c}$ Centre for Epidemiologic Studies Depression Scale, higher scores indicate higher levels of depression.

often reported early-morning awakening. Participants with long sleep duration ( $\geq 9$ hours) were the oldest, had the highest Framingham scores and the lowest education years. Alcohol consumption and depression scores were highest and physical activity the lowest in persons with 5 or less hours of nocturnal sleep duration.

Sleep quality and PSQI score. A PSQI score $>5$ was associated with an increased risk for MCI $(\mathrm{RR}=1.43$, 95\% CI: 1.12 to 1.82$)$ ) in the fully adjusted model with multiple imputations, see Table 3 . This was confirmed when the PSQI score was used as a continuous variable $(R R=1.05$ (1.01 to 1.08$))$.

Sleep disturbances. After multiple imputation, the relative risk for MCI was increased for persons experiencing difficulties initiating sleep almost every night $(\mathrm{RR}=1.40(0.94$ to 2.08$))$, but not for experiencing difficulties maintaining sleep and early morning awakening, respectively (cf. Table 3 ).

Sleep duration. We observed a U-shaped association between time in bed during the night and incident MCI as well as between total sleep duration (time in bed during the night plus daytime napping) and incident MCI (cf. Table 4, cf. Fig. 2). For nocturnal time in bed, persons who spent $\leq 5$ hours in bed, and persons who spent $\geq$ 9 hours in bed were more likely to develop MCI than persons who spent 7 to $<8$ hours in bed (RR $=2.86$ (95\% CI: 1.24 to 6.60 ), and $\mathrm{RR}=1.30$ (95\% CI: 0.93 to 1.82 ), respectively). For time asleep (which does not include time awake in bed) results were different: The RR for incident MCI was 1.19 (95\% CI: 0.83 to 1.72) for persons with $\leq$ 5 hours of time asleep, and it was 0.70 ( 0.32 to 1.54$)$ for persons with $\geq 9$ hours.

Multiple imputations. The use of multiple imputations (MI) yielded different results compared to the complete case (CC) analysis. MI resulted in more precise estimations. The $95 \%$ CIs in the MI analysis were on average $13 \%$ smaller. Point estimates for some of the relative risks diverged.

Additional analyses. We calculated change of sleep duration between T1 and T0 from sleep duration measured at T1 and T0. Persons who reported shorter nocturnal or total sleep duration at T1 compared to T0 had a higher risk of MCI: a decrease of sleep duration of at least one hour was associated with a 1.23 (1.00 to 1.51) and 1.26 (1.02 to 1.55) fold MCI risk for change of nocturnal and total sleep duration, respectively (cf. Table 5). In 


\begin{tabular}{|c|c|c|c|c|c|c|c|c|}
\hline \multirow[b]{2}{*}{ Exposure } & & \multicolumn{4}{|c|}{ Complete Case Analysis $(\mathrm{N}=1890)$} & \multicolumn{3}{|c|}{$\begin{array}{l}\text { Multiple Imputation } \\
(\mathrm{N}=\mathbf{2 4 8 0})\end{array}$} \\
\hline & & $\mathbf{N}$ & n (\%) & RR & $95 \% \mathrm{CI}$ & n \% & RR & $95 \% \mathrm{CI}$ \\
\hline \multirow{2}{*}{$\begin{array}{l}\text { Sleep Quality: } \\
\text { PSQI Score }\end{array}$} & $\leq 5($ good $)$ & 1143 & $105(9.2 \%)$ & 1.00 & Reference & $9.0 \%$ & 1.00 & Reference \\
\hline & $>5$ (poor) & 747 & $96(12.9 \%)$ & 1.38 & \begin{tabular}{|l}
{$[1.06$ to } \\
$1.80]$
\end{tabular} & $13.5 \%$ & 1.43 & \begin{tabular}{|l|}
{$[1.12$ to } \\
$1.82]$
\end{tabular} \\
\hline \multirow{4}{*}{$\begin{array}{l}\text { Difficulties } \\
\text { Initiating Sleep }\end{array}$} & Never & 747 & $75(10.0 \%)$ & 1.00 & Reference & $10.0 \%$ & 1.00 & Reference \\
\hline & Sometimes & 689 & $70(10.2 \%)$ & 1.04 & $\begin{array}{l}{[0.76 \text { to }} \\
1.42]\end{array}$ & $10.0 \%$ & 1.02 & $\begin{array}{l}{[0.78 \text { to }} \\
1.35]\end{array}$ \\
\hline & Often & 316 & $35(11.1 \%)$ & 1.12 & $\begin{array}{l}{[0.76 \text { to }} \\
1.64]\end{array}$ & $12.8 \%$ & 1.25 & $\begin{array}{l}{[0.91 \text { to }} \\
1.72]\end{array}$ \\
\hline & $\begin{array}{l}\text { Almost } \\
\text { every Night }\end{array}$ & 138 & $21(15.2 \%)$ & 1.46 & $\begin{array}{l}{[0.94 \text { to }} \\
2.28]\end{array}$ & $15.2 \%$ & 1.40 & $\begin{array}{l}{[0.94 \text { to }} \\
2.08]\end{array}$ \\
\hline \multirow{4}{*}{$\begin{array}{l}\text { Difficulties } \\
\text { Maintaining } \\
\text { Sleep }\end{array}$} & Never & 195 & $20(10.3 \%)$ & 1.00 & Reference & $10.6 \%$ & 1.00 & Reference \\
\hline & Sometimes & 466 & $41(8.8 \%)$ & 0.89 & $\begin{array}{l}{[0.54 \text { to }} \\
1.47]\end{array}$ & $9.2 \%$ & 0.85 & $\begin{array}{l}{[0.56 \text { to }} \\
1.31]\end{array}$ \\
\hline & Often & 508 & $50(9.8 \%)$ & 0.96 & $\begin{array}{l}{[0.59 \text { to }} \\
1.56]\end{array}$ & $10.2 \%$ & 0.91 & $\begin{array}{l}{[0.60 \text { to }} \\
1.37]\end{array}$ \\
\hline & $\begin{array}{l}\text { Almost } \\
\text { every Night }\end{array}$ & 721 & $90(12.5 \%)$ & 1.10 & $\begin{array}{l}{[0.70 \text { to }} \\
1.72]\end{array}$ & $12.5 \%$ & 1.04 & $\begin{array}{l}{[0.71 \text { to }} \\
1.52]\end{array}$ \\
\hline \multirow{4}{*}{$\begin{array}{l}\text { Early Morning } \\
\text { Awakening }\end{array}$} & Never & 770 & $79(10.3 \%)$ & 1.00 & Reference & $10.4 \%$ & 1.00 & Reference \\
\hline & Sometimes & 595 & $58(9.7 \%)$ & 0.99 & $\begin{array}{l}{[0.72 \text { to }} \\
1.37]\end{array}$ & $10.0 \%$ & 0.99 & $\begin{array}{l}{[0.75 \text { to }} \\
1.30]\end{array}$ \\
\hline & Often & 349 & $46(13.2 \%)$ & 1.30 & $\begin{array}{l}{[0.92 \text { to }} \\
1.84]\end{array}$ & $13.3 \%$ & 1.25 & $\begin{array}{l}{[0.93 \text { to }} \\
1.69]\end{array}$ \\
\hline & $\begin{array}{l}\text { Almost } \\
\text { every Night }\end{array}$ & 176 & $18(10.2 \%)$ & 0.99 & \begin{tabular}{|l|}
{$[0.61$ to } \\
$1.60]$
\end{tabular} & $10.9 \%$ & 0.99 & \begin{tabular}{|l|}
{$[0.66$ to } \\
$1.50]$
\end{tabular} \\
\hline
\end{tabular}

Table 3. Adjusted relative risks for the association between sleep quality, and sleep disturbances, respectively, and the incidence of mild cognitive impairment at t2: the Heinz Nixdorf Recall Study. Estimates of relative risks with $95 \%$ confidence intervals were obtained from a log-linear model with a Poisson working likelihood and robust standard errors. Abbreviations: t1: second visit in the Heinz Nixdorf Recall Study (HNR Study); t2: third visit in the HNR Study; RR: relative risk; $\mathrm{n} \%$ : percent of cases; CI: Confidence Interval. Model is adjusted for age (cont.) and sex (male/female), height (cont.), waist (cont.), Framingham CVD risk score (cont.), smoking status (never/former/current), ISC education years (cont.), physical activity (cont.; MET-h/week), pure alcohol consumption (cont.; g/week), APOE e4 genotype (carrier/non-carrier), and depression score (cont.).

age-stratified analyses, the U-shaped association between time in bed and total sleep duration and incident MCI was strongly pronounced in the two older age groups ( 55 to 64,65 to 74 years), but not in the youngest. However, in the youngest group ( 45 to 54 years), an increased MCI risk was not observed for any sleep duration parameter, but more strongly for sleep quality parameters (cf. appendix 6). In the analysis stratified by the APOE carrier status, we observed a stronger influence of difficulties maintaining sleep, early morning awakening and sleep quality in non-carriers, e.g. for PSQI Score > 5, the RR was 1.61 (1.28 to 2.02) in non-carriers compared to 1.21 ( 0.82 to 1.76) in carriers. For carriers, on the other hand, short sleep duration had a larger effect on MCI risk: for $\leq 5 \mathrm{~h}$ of total sleep duration, the RR was 2.20 (1.22 to 3.96) in carriers compared to 1.52 (1.05 to 2.20) in non-carriers (cf. appendix 7).

\section{Discussion}

In our prospective cohort study, a higher risk of MCI was observed in persons with self-reported poor overall sleep quality, in persons who reported short time in bed, and persons with a strong decrease of sleep duration before baseline. Moreover, persons who reported difficulties initiating sleep almost every night had a higher risk of incident MCI five years later. For persons reporting difficulties maintaining sleep or early morning awakening, the risk for MCI was not increased.

Results for sleep duration depended on whether time awake in bed was included or excluded in the calculation for sleep duration: For persons with short or long time asleep, there was no evidence of higher MCI risk. In contrast, the association between time in bed and incident MCI was U-shaped; however, for $\leq 5$ hours of time in bed, this association was based on very few participants. The reason why relative risks for long sleep duration $(\geq$ 9 hours) differ for time in bed and time asleep may be that persons for whom time in bed is much longer than time asleep more often have some form of sleep disturbance. This in line with the 2014 study by Blackwell et al. who found that self-reported long sleep durations were associated with short measured sleep duration and fragmented sleep in elderly men ${ }^{37}$. The differences between time in bed and time asleep for short sleep duration may be due to the fact that persons reporting $\leq 5$ hours of time in bed probably suffer more from lack of sleep than persons who are actually asleep during the same time interval.

Persons with a strong decrease of sleep duration at first follow-up compared to baseline had a higher risk of MCI. This may be explained by the observation that many of these persons have become short sleepers: about $60 \%$ of persons with subjective sleep duration $\leq 5$ hours at follow-up reported a decrease of sleep duration of at least one hour. However, whether change of sleep duration itself or short sleep duration is the primary cause of higher MCI risk cannot be answered by our study. 


\begin{tabular}{|c|c|c|c|c|c|c|c|c|}
\hline \multirow[b]{2}{*}{ Exposure } & & \multicolumn{4}{|c|}{ Complete Case Analysis $(\mathrm{N}=1890)$} & \multicolumn{3}{|c|}{$\begin{array}{l}\text { Multiple Imputation } \\
(\mathrm{N}=\mathbf{2 4 8 0})\end{array}$} \\
\hline & & $\mathbf{N}$ & n (\%) & RR & 95\% CI & n \% & RR & $95 \% \mathrm{CI}$ \\
\hline \multirow{5}{*}{$\begin{array}{l}\text { Time in bed } \\
\text { during the } \\
\text { night }^{\mathrm{a}}\end{array}$} & $\leq 5 \mathrm{~h}$ & 13 & $3(23.1 \%)$ & 3.14 & \begin{tabular}{|l}
{$[1.16$ to } \\
$8.49]$
\end{tabular} & $22.8 \%$ & 2.86 & \begin{tabular}{|l|}
{$[1.24$ to } \\
$6.60]$
\end{tabular} \\
\hline & $\begin{array}{l}>5 \mathrm{~h} \\
\text { to } \\
<7 \mathrm{~h}\end{array}$ & 209 & $13(6.2 \%)$ & 0.82 & $\begin{array}{l}{[0.45 \text { to }} \\
1.50]\end{array}$ & $8.1 \%$ & 0.96 & $\begin{array}{l}{[0.56 \text { to }} \\
1.64]\end{array}$ \\
\hline & $\begin{array}{l}7 \mathrm{~h} \text { to } \\
<8 \mathrm{~h}\end{array}$ & 472 & $40(8.5 \%)$ & 1.00 & Reference & $9.0 \%$ & 1.00 & Reference \\
\hline & $\begin{array}{l}8 \mathrm{~h} \text { to } \\
<9 \mathrm{~h}\end{array}$ & 655 & $70(10.7 \%)$ & 1.09 & $\begin{array}{l}{[0.75 \text { to }} \\
1.59]\end{array}$ & $10.7 \%$ & 1.08 & \begin{tabular}{|l}
{$[0.77$ to } \\
$1.52]$
\end{tabular} \\
\hline & $\geq 9 \mathrm{~h}$ & 535 & $75(14.0 \%)$ & 1.33 & \begin{tabular}{|l}
{$[0.92$ to } \\
$1.94]$
\end{tabular} & $13.4 \%$ & 1.30 & \begin{tabular}{|l|}
{$[0.93$ to } \\
$1.82]$
\end{tabular} \\
\hline \multirow{5}{*}{ Time asleep $^{\mathrm{b}}$} & $\leq 5 \mathrm{~h}$ & 209 & $28(13.4 \%)$ & 1.28 & \begin{tabular}{|l}
{$[0.86$ to } \\
$1.90]$
\end{tabular} & $13.5 \%$ & 1.19 & \begin{tabular}{|l|}
{$[0.83$ to } \\
$1.72]$
\end{tabular} \\
\hline & $\begin{array}{l}>>5 \mathrm{~h} \\
\text { to } \\
<7 \mathrm{~h}\end{array}$ & 612 & $58(9.5 \%)$ & 0.91 & $\begin{array}{l}{[0.65 \text { to }} \\
1.26]\end{array}$ & $10.0 \%$ & 0.91 & \begin{tabular}{|l}
{$[0.69$ to } \\
$1.22]$
\end{tabular} \\
\hline & $\begin{array}{l}7 \mathrm{~h} \text { to } \\
<8 \mathrm{~h}\end{array}$ & 655 & $71(10.8 \%)$ & 1.00 & Reference & $11.2 \%$ & 1.00 & Reference \\
\hline & $\begin{array}{l}8 \mathrm{~h} \text { to } \\
<9 \mathrm{~h}\end{array}$ & 352 & $39(11.1 \%)$ & 0.90 & \begin{tabular}{|l}
{$[0.62$ to } \\
$1.30]$
\end{tabular} & $10.7 \%$ & 0.88 & \begin{tabular}{|l|}
{$[0.63$ to } \\
$1.24]$
\end{tabular} \\
\hline & $\geq 9 \mathrm{~h}$ & 62 & $5(8.1 \%)$ & 0.66 & \begin{tabular}{|l}
{$[0.28$ to } \\
$1.59]$
\end{tabular} & $8.5 \%$ & 0.70 & \begin{tabular}{|l|}
{$[0.32$ to } \\
$1.54]$
\end{tabular} \\
\hline \multirow{5}{*}{$\begin{array}{l}\text { Total Sleep } \\
\text { Duration }{ }^{\mathrm{a}, \mathrm{c}}\end{array}$} & $\leq 5 \mathrm{~h}$ & 7 & $2(28.6 \%)$ & 2.01 & $\begin{array}{l}{[1.27 \text { to }} \\
3.19]\end{array}$ & $21.8 \%$ & 2.63 & \begin{tabular}{|l|}
{$[0.70$ to } \\
$9.85]$
\end{tabular} \\
\hline & $\begin{array}{l}>5 \mathrm{~h} \\
\text { to } \\
<7 \mathrm{~h}\end{array}$ & 198 & $13(6.6 \%)$ & 1.09 & $\begin{array}{l}{[0.75 \text { to }} \\
1.58]\end{array}$ & $8.9 \%$ & 1.11 & $\begin{array}{l}{[0.65 \text { to }} \\
1.92]\end{array}$ \\
\hline & $\begin{array}{l}7 \mathrm{~h} \text { to } \\
<8 \mathrm{~h}\end{array}$ & 447 & $33(7.4 \%)$ & 1.00 & Reference & $8.4 \%$ & 1.00 & Reference \\
\hline & $\begin{array}{l}8 \mathrm{~h} \text { to } \\
<9 \mathrm{~h}\end{array}$ & 627 & $71(11.3 \%)$ & 1.35 & \begin{tabular}{|l}
{$[0.95$ to } \\
$1.92]$
\end{tabular} & $11.1 \%$ & 1.19 & \begin{tabular}{|l|}
{$[0.83$ to } \\
$1.70]$
\end{tabular} \\
\hline & $\geq 9 \mathrm{~h}$ & 605 & $82(13.6 \%)$ & 1.65 & $\begin{array}{l}{[1.01 \text { to }} \\
2.68]\end{array}$ & $13.0 \%$ & 1.31 & \begin{tabular}{|l|}
{$[0.92$ to } \\
$1.85]$
\end{tabular} \\
\hline
\end{tabular}

Table 4. Adjusted relative risks for the association between subjective sleep duration and the incidence of mild cognitive impairment at $\mathrm{t} 2$ : the Heinz Nixdorf Recall Study. Estimates of relative risks with $95 \%$ confidence intervals were obtained from a log-linear model with a Poisson working likelihood and robust standard errors. Abbreviations: t1: second visit in the Heinz Nixdorf Recall Study (HNR Study); t2: third visit in the HNR Study; RR: relative risk; $\mathrm{n} \%$ : percent of cases; CI: Confidence Interval Model is adjusted for age (cont.) and sex (male/ female), height (cont.), waist (cont.), Framingham CVD risk score (cont.), smoking status (never/former/ current), ISC education years (cont.), physical activity (cont.; MET-h/week), pure alcohol consumption (cont.;

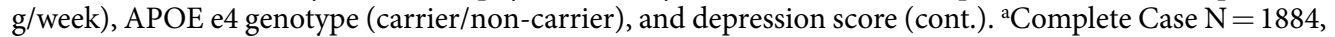
because of 6 additional missing data for time in bed. ${ }^{b}$ Time asleep does not include time awake in bed. ${ }^{c}$ Total sleep duration includes time in bed during the night plus daytime napping.

Our results based on longitudinal HNR Study data are in line with earlier cross-sectional analyses of the same cohort. Dlugaj et al. (2014) ${ }^{11}$ reported an increased Odds Ratio (OR) for MCI in participants with poor sleep quality $(\mathrm{OR}=1.30$ [1.02 to 2.03]). Poor sleep quality, however, was defined as at least one sleep disturbance reported 'almost every night' in contrast to a PSQI score of $>5$ in the present analysis. Regarding sleep disturbances (identical item), results from the earlier cross-sectional study could be replicated in the present longitudinal study.

Similar results have also been reported in two other prospective studies on sleep patterns and cognitive decline. Potvin et al. $(2012)^{38}$ found an increased OR for incidence of cognitive impairment at 12 months for men with $\leq 5 \mathrm{~h}$ of sleep $(\mathrm{OR}=2.91$ [1.24 to 6.82 ], reference $>5$ to $<9 \mathrm{~h})$. In another prospective analysis, Keage et al. $(2012)^{39}$ reported an increased relative risk for cognitive impairment when comparing $\leq 6.5 \mathrm{~h}$ to $>6.5$ to $<8.5 \mathrm{~h}(\mathrm{RR}=2.02$ [1.1.7 to 3.48$])$ and $\geq 8.5 \mathrm{~h}$ to $>6.5$ to $<8.5 \mathrm{~h}(\mathrm{RR}=1.27$ [0.64 to 2.48]) of nocturnal sleep. Regarding long sleep duration, several studies showed long sleep to be associated with impaired cognitive performance ${ }^{13,40-42}$. For instance, Ramos et al. (2019) ${ }^{40}$ found long sleep ( $>9$ hours) to be predictive for seven-year cognitive decline in episodic learning and memory. Potvin et al. (2012) ${ }^{38}$ reported an increased OR for women sleeping $\geq 9 \mathrm{~h}(\mathrm{OR}=2.10$ [1.10 to 4.00$]$, reference $>5$ to $<9 \mathrm{~h})$. However, most studies also used self-reported sleep duration and did not explicitly exclude time awake in bed from their sleep duration calculation. In concordance, a specific pathway between long sleep duration and cognitive decline is not known. Long sleep duration is associated with cerebrovascular disease ${ }^{43,44}$ which is a contributor to cognitive impairment and cognitive decline $^{45,46}$. Persons with cardiovascular disease have more often problems in maintaining sleep ${ }^{47,48}$. When hours awake in bed are not explicitly excluded, those persons might tend to recall longer sleep durations without 


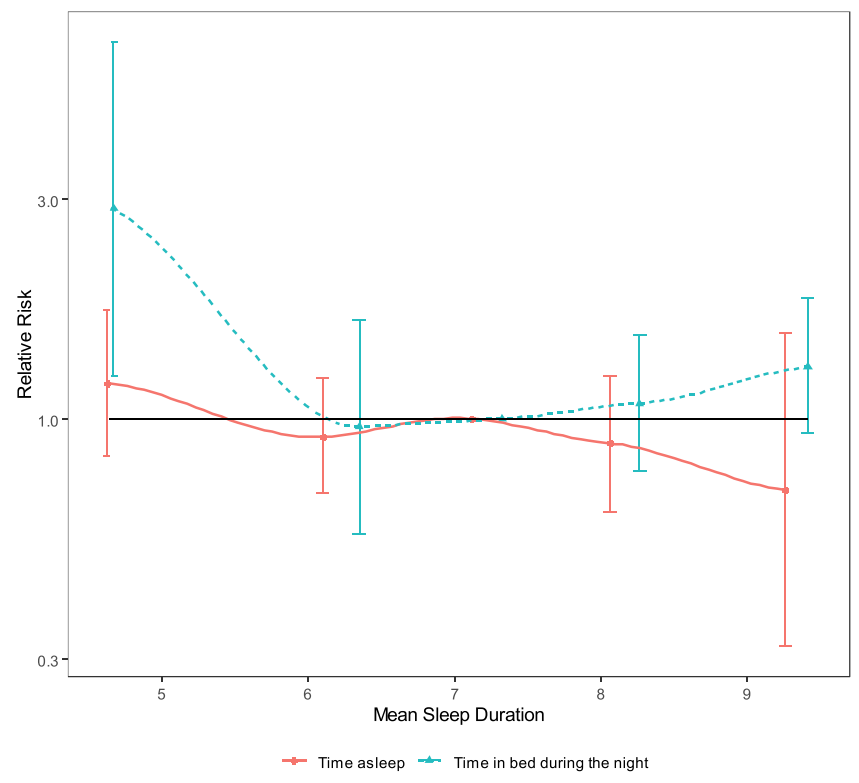

Figure 2. Relative Risks for Mild Cognitive Impairment: The Heinz Nixdorf Recall Study. Estimates of relative risk were obtained from log-linear model with a Poisson working likelihood and robust standard errors. Missing values were imputed. Sleep duration was assesed as a categorical variable. Dots are the means of their respective category. Categories were: $\leq 5 \mathrm{~h} \mid>5$ to $<7 \mathrm{~h} \mid 7$ to $<8 \mathrm{~h}$ (reference) $\mid 8$ to $<9 \mathrm{~h} \mid \geq 9 \mathrm{~h}$.

\begin{tabular}{|l|l|l|l|}
\hline Exposure & & RR & 95\% CI \\
\hline \multirow{2}{*}{$\begin{array}{l}\text { Change of } \\
\text { nocturnal sleep } \\
\text { duration }\end{array}$} & $\leq-1 \mathrm{~h}$ & 1.23 & {$[1.00$ to 1.51$]$} \\
\cline { 2 - 4 } & $<-1 \mathrm{~h}$ to $<+1 \mathrm{~h}$ & 1.00 & Reference \\
\cline { 2 - 4 } & $\geq+1 \mathrm{~h}$ & 0.98 & {$[0.78$ to 1.23$]$} \\
\hline \multirow{3}{*}{$\begin{array}{l}\text { Change of total } \\
\text { sleep duration }\end{array}$} & $\leq-1 \mathrm{~h}$ & 1.26 & {$[1.02$ to 1.55$]$} \\
\cline { 2 - 4 } & $<-1 \mathrm{~h}$ to $<+1 \mathrm{~h}$ & 1.00 & Reference \\
\cline { 2 - 4 } & $\geq+1 \mathrm{~h}$ & 0.92 & {$[0.73$ to 1.16$]$} \\
\hline
\end{tabular}

Table 5. Relative Risks of Incident MCI for Changes in Sleep Duration Between First and Second Visit to the Study Center: the Heinz Nixdorf Recall Study ${ }^{\mathrm{a}}$. Estimates of relative risks with $95 \%$ confidence intervals were obtained from a log-linear model with a Poisson working likelihood and robust standard errors. RR: Relative Risk; CI: confidence interval. Model is adjusted for age (cont.) and sex (male/female) height (cont.), waist (cont.), Framingham CVD risk score (cont.), smoking status (never/former/current), ISC education years (cont.), physical activity (cont.; meth/week), pure alcohol consumption (cont.; g/week), and depression score (cont.). ${ }^{a}$ Multiple imputation was used for analyses b ${ }^{b}$ Sleep differences were calculated subtracting baseline sleeping time from $\mathrm{T} 1$ sleeping time.

subtracting time awake in bed. This might be an explanation for the vanished U-shaped association in our cohort. However, this finding has to be confirmed in studies with objective sleep measurements and incident MCI.

Our results fit well into the literature on sleep characteristics and cognitive impairment. Overall with increasing age, a dysregulation of the sleep-wake cycle resulting in more fragmented and shorter sleep is common ${ }^{49}$. Regarding cognitive impairment, associations with poor sleep have been found for all stages: for the preclinical stage which precedes observable cognitive impairment and which encompasses tau accumulation, beta amyloid accumulation and neurodegeneration ${ }^{50}$, for MCI like in the present study, and for manifest $\mathrm{AD}^{16,50}$. The direction of these associations, however, is hypothesized to be bi-directional ${ }^{12,51,52}$.

A possible mechanism for this bi-directional relationship is an interdependent cycle of brain matter damage and sleep disturbances ${ }^{12,52,53}$. The basal forebrain is responsible for sleep promotion in humans ${ }^{54}$. In MCI and $\mathrm{AD}$ patients, an early cell loss in this brain region was described and associated with a decline in sleep quality $^{55,56}$. Thus, sleep problems might be a result of neurodegeneration. However, the decline in sleep quality is also associated with an increase in beta amyloid deposits (a hallmark of AD) leading to faster disease progres$\operatorname{sion}^{51,57}$. Increased beta amyloid levels in the brain impair slow-wave sleep leading to sleep problems ${ }^{58,59}$, thus sleep problems might be a correlate of neurodegeneration. However, even in cognitively healthy participants a shorter sleep duration and poor sleep quality was associated with beta amyloid burden ${ }^{60}$. In concordance, animal models showed that sleep deprivation increases interstitial fluid beta amyloid levels ${ }^{61,62}$. These studies indicate that poor sleep might also promote beta amyloid deposition and neurocognitive decline and impairment. This is in line with recent evidence of self-reported sleep with higher rates of hippocampal volume decline in cognitively normal participants ${ }^{63}$. 
Overall, the association between sleep and brain health is very complex. A recent review by van Egroo et al. $(2019)^{50}$ summarizes the current evidence on the hallmarks of the pathogenesis of AD and sleep. In addition to the association of sleep and beta amyloid mentioned above, animal models showed that neuronal activity as observed during extended wakefulness or chronic sleep restriction could lead to an increase in tau produc$\operatorname{tion}^{64-66}$. However, it is also difficult to identify the directionality of the interplay between tau and sleep patterns in human because radiotracers for tau were not available until recently ${ }^{67,68}$. It is further discussed that sleep deprivation induce inflammatory responses that could adversely affect cognitive function ${ }^{69}$. Increased inflammatory processes also play a major role in $\mathrm{AD}^{70}$. Many of these factors show an interaction with beta amyloid and with the Apolipoprotein E genotype making this association even more complex ${ }^{71-74}$. Thus, the bi-directional pathways have to be further elucidated in studies with objective sleep measures and biomarker information throughout the life span.

Taken together, given the high prevalence of sleep problems in the elderly population and the increased prevalence of dementia cases, sleep disturbances might serve as a preclinical marker to identify individuals at risk for cognitive decline. Even when the causality is not fully understood yet, improving sleep might be a useful, reasonable and easy to administer strategy to improve brain health.

Strengths and limitations. Strengths of our study include its population-based cohort, a large study size, its prospective design with extensive phenotyping of participants, and the in-depth measurement of cognitive abilities. Moreover, we compared different items for sleep duration, which has not been done in other studies.

A limitation of the present study is the subjective assessment of sleep patterns. However, contrary to objective measurements, self-reported sleep data do not rely on the peculiarities of a few nights in an unfamiliar environment, but rather reflect longer time periods (like, e.g., four weeks in the PSQI sleep item) ${ }^{75}$. Additionally, for a single night the subjective assessment from the PSQI has been shown to be comparable to polysomnography and actigraphy measurements by Zinkhan et al. $(2014)^{76}$. Because this is a longitudinal study with cognitive data assessed at the first and second follow-up examination, cognitively impaired participants were less likely to participate resulting in a cohort representing a healthier population ${ }^{77}$. MCI was not based on clinical consensus. However, we validated the short cognitive performance assessment at $\mathrm{t} 1$ against a detailed neuropsychological and neurological examination in a subsample of 656 participants and observed a good accuracy in identifying MCI (area under the curve $(\mathrm{AUC})=0.82,95 \%$ confidence interval $(\mathrm{CI})=0.78-0.85)^{26}$. The definition of objective cognitive impairment for the MCI diagnosis changed between $\mathrm{t} 1$ and $\mathrm{t} 2$. At $\mathrm{t} 2$, we were able to define cognitive domain scores for our incident MCI diagnosis as requested by Albert et al. ${ }^{78}$. Finally, we do not have any biomarker information to differentiate between underlying pathologies for incident MCI.

Future research. A major limitation of our work is the use of subjective sleep data. For future research, objective sleep data should additionally be used. Moreover, some sleep characteristics have rarely been investigated as potential risk factors for cognitive decline like napping and sleep apnea. In earlier work, we had already investigated the association between sleep disordered breathing and MCI in a cross-sectional study where we observed a null-result [12]. For future research, a study on prevalence of sleep apnea or sleep disordered breathing and incident MCI might be a topic of interest.

\section{Conclusion}

We found an association between various indicators for poor sleep and incident MCI. These results underline the importance of sleep for health outcomes.

\section{Data availability}

Data of the Heinz Nixdorf Recall Study can be obtained by filling a request for data use and explaining the aim of the planned analyses.

Received: 10 September 2019; Accepted: 27 March 2020;

Published online: 16 April 2020

\section{References}

1. Prince, M. et al. The global prevalence of dementia: a systematic review and metaanalysis. Alzheimer's \& dementia: the journal of the Alzheimer's Association 9, 63-75.e2, https://doi.org/10.1016/j.jalz.2012.11.007 (2013).

2. Alzheimer's Disease International. Policy Brief for G8 Heads of Government. The Global Impact of Dementia 2013-2050 (2013).

3. 2016 Alzheimer's disease facts and figures. Alzheimer's \& dementia: the journal of the Alzheimer's Association 12, 459-509; https:// doi.org/10.1016/j.jalz.2016.03.001 (2016).

4. Wu, Y.-T. et al. Dementia in western Europe: epidemiological evidence and implications for policy making. The Lancet Neurology 15, 116-124, https://doi.org/10.1016/S1474-4422(15)00092-7 (2016).

5. Norton, S., Matthews, F. E., Barnes, D. E., Yaffe, K. \& Brayne, C. Potential for primary prevention of Alzheimer's disease: an analysis of population-based data. The Lancet Neurology 13, 788-794, https://doi.org/10.1016/S1474-4422(14)70136-X (2014).

6. Virta, J. J. et al. Midlife sleep characteristics associated with late life cognitive function. Sleep 36, 1533-41, 1541A, https://doi. org/10.5665/sleep.3052 (2013).

7. van Oostrom, S. H., Nooyens, A. C. J., van Boxtel, M. P. J. \& Verschuren, W. M. M. Long sleep duration is associated with lower cognitive function among middle-age adults - the Doetinchem Cohort Study. Sleep medicine 41, 78-85, https://doi.org/10.1016/j. sleep.2017.07.029 (2018).

8. Ramos, A. R. et al. Sleep disturbances and cognitive decline in the Northern Manhattan Study. Neurology 87, 1511-1516, https://doi. org/10.1212/WNL.0000000000003168 (2016).

9. Lo, J. C., Groeger, J. A., Cheng, G. H., Dijk, D.-J. \& Chee, M. W. L. Self-reported sleep duration and cognitive performance in older adults. A systematic review and meta-analysis. Sleep medicine 17, 87-98, https://doi.org/10.1016/j.sleep.2015.08.021 (2016).

10. Johar, H., Kawan, R., Emeny, R. T. \& Ladwig, K.-H. Impaired Sleep Predicts Cognitive Decline in Old People. Findings from the Prospective KORA Age Study. Sleep 39, 217-226, https://doi.org/10.5665/sleep.5352 (2016). 
11. Dlugaj, M. et al. Sleep-disordered breathing, sleep quality, and mild cognitive impairment in the general population. Journal of Alzheimer's disease: JAD 41, 479-497, https://doi.org/10.3233/JAD-132132 (2014).

12. Devore, E. E., Grodstein, F. \& Schernhammer, E. S. Sleep Duration in Relation to Cognitive Function among Older Adults. A Systematic Review of Observational Studies. Neuroepidemiology 46, 57-78, https://doi.org/10.1159/000442418 (2016).

13. Chen, J.-C. et al. Sleep duration, cognitive decline, and dementia risk in older women. Alzheimer's \& dementia: the journal of the Alzheimer's Association 12, 21-33, https://doi.org/10.1016/j.jalz.2015.03.004 (2016).

14. Kuperczkó, D. et al. Late bedtime is associated with decreased hippocampal volume in young healthy subjects. Sleep and Biological Rhythms 13, 68-75, https://doi.org/10.1111/sbr.12077 (2015).

15. Sabeti, S., Al-Darsani, Z., Mander, B. A., Corrada, M. M. \& Kawas, C. H. Sleep, hippocampal volume, and cognition in adults over 90 years old. Aging clinical and experimental research 30, 1307-1318, https://doi.org/10.1007/s40520-018-1030-x (2018).

16. Bubu, O. M. et al. Sleep, Cognitive impairment, and Alzheimer's disease. A Systematic Review and Meta-Analysis. Sleep 40; https:// doi.org/10.1093/sleep/zsw032 (2017).

17. Sindi, S. et al. Sleep disturbances and dementia risk: A multicenter study. Alzheimer's \& dementia: the journal of the Alzheimer's Association 14, 1235-1242, https://doi.org/10.1016/j.jalz.2018.05.012 (2018).

18. Westwood, A. J. et al. Prolonged sleep duration as a marker of early neurodegeneration predicting incident dementia. Neurology 88, 1172-1179, https://doi.org/10.1212/WNL.0000000000003732 (2017)

19. Jackowska, M. \& Cadar, D. The mediating role of low-grade inflammation on the prospective association between sleep and cognitive function in older men and women: 8-year follow-up from the English Longitudinal Study of Ageing. Archives of gerontology and geriatrics 87, 103967, https://doi.org/10.1016/j.archger.2019.103967 (2019).

20. Stang, A. et al. Baseline recruitment and analyses of nonresponse of the Heinz Nixdorf recall study. Identifiability of phone numbers as the major determinant of response. Eur J Epidemiol 20, 489-496, https://doi.org/10.1007/s10654-005-5529-z (2005).

21. Schmermund, A. et al. Assessment of clinically silent atherosclerotic disease and established and novel risk factors for predicting myocardial infarction and cardiac death in healthy middle-aged subjects. Rationale and design of the Heinz Nixdorf RECALL Study. American Heart Journal 144, 212-218, https://doi.org/10.1067/mhj.2002.123579 (2002).

22. Oswald, W. D. \& Fleischmann, U. M. Nürnberger-Alters-Inventar (NAI). NAI-Testmanual und-Textband (Verlag für Psychologie, Hogrefe, 1999)

23. Aschenbrenner, S., Tucha, O. \& Lange, K. W. Regensburger Wortflüssigkeits-Test. RWT (Hogrefe Verl. für Psychologie, Göttingen, 2000).

24. Shulman, K. I. Clock-drawing. Is it the ideal cognitive screening test? International journal of geriatric psychiatry 15, 548-561; 10.1002/1099-1166(200006)15:6<548::AID-GPS242>3.0.CO;2-U (2000).

25. Reitan, R. M. The relation of the trail making test to organic brain damage. Journal of consulting psychology 19, 393-394, https://doi. org $/ 10.1037 / \mathrm{h} 0044509$ (1955)

26. Wege, N. et al. Population-based distribution and psychometric properties of a short cognitive performance measure in the population-based Heinz Nixdorf Recall Study. Neuroepidemiology 37, 13-20, https://doi.org/10.1159/000328262 (2011).

27. Tebrügge, S. et al. Olfactory Function is Associated with Cognitive Performance: Results of the Heinz Nixdorf Recall Study. Journal of Alzheimer's disease: JAD 63, 319-329, https://doi.org/10.3233/JAD-170863 (2018).

28. Müller-Gerards, D. et al. Subjective cognitive decline, APOE $\varepsilon 4$, and incident mild cognitive impairment in men and women. Alzheimer's \&. dementia (Amsterdam, Netherlands) 11, 221-230, https://doi.org/10.1016/j.dadm.2019.01.007 (2019).

29. Petersen, R. C. Mild cognitive impairment as a diagnostic entity. Journal of internal medicine 256, 183-194, https://doi.org/10.1111/ j.1365-2796.2004.01388.x (2004).

30. Winblad, B. et al. Mild cognitive impairment-beyond controversies, towards a consensus. Report of the International Working Group on Mild Cognitive Impairment. Journal of internal medicine 256, 240-246, https://doi.org/10.1111/j.1365-2796.2004.01380.x (2004).

31. Buysse, D. J., Reynolds, C. F., Monk, T. H., Berman, S. R. \& Kupfer, D. J. The Pittsburgh sleep quality index. A new instrument for psychiatric practice and research. Psychiatry research 28, 193-213, https://doi.org/10.1016/0165-1781(89)90047-4 (1989).

32. Hirshkowitz, M. et al. National Sleep Foundation's sleep time duration recommendations. Methodology and results summary. Sleep health 1, 40-43, https://doi.org/10.1016/j.sleh.2014.12.010 (2015).

33. Textor, J., van der Zander, B., Gilthorpe, M. S., Liskiewicz, M. \& Ellison, G. T. Robust causal inference using directed acyclic graphs. The R package 'dagitty'. International journal of epidemiology 45, 1887-1894, https://doi.org/10.1093/ije/dyw341 (2016).

34. Hautzinger, M. \& Bailer, M. Allgemeine Depressionsskala (ADS). Beltz Test (Weinheim, 1993).

35. Zou, G. A. Modified Poisson Regression Approach to Prospective Studies with Binary Data. American Journal of Epidemiology 159, 702-706, https://doi.org/10.1093/aje/kwh090 (2004)

36. Spiegelman, D. \& Hertzmark, E. Easy SAS calculations for risk or prevalence ratios and differences. American Journal of Epidemiology 162, 199-200, https://doi.org/10.1093/aje/kwi188 (2005).

37. Blackwell, T. et al. Associations of objectively and subjectively measured sleep quality with subsequent cognitive decline in older community-dwelling men. The MrOS sleep study. Sleep 37, 655-663, https://doi.org/10.5665/sleep.3562 (2014).

38. Potvin, O. et al. Sleep quality and 1-year incident cognitive impairment in community-dwelling older adults. Sleep 35, 491-499, https://doi.org/10.5665/sleep.1732 (2012).

39. Keage, H. A. D. et al. What sleep characteristics predict cognitive decline in the elderly? Sleep medicine 13, $886-892$, https://doi. org/10.1016/j.sleep.2012.02.003 (2012).

40. Ramos, A. R. et al. Sleep and neurocognitive decline in the Hispanic Community Health Study/Study of Latinos. Alzheimer's \&. dementia: the journal of the Alzheimer's Association https://doi.org/10.1016/j.jalz.2019.08.191 (2019).

41. Kim, H.-B., Myung, S.-K., Lee, S.-M. \& Park, Y. C. Longer Duration of Sleep and Risk of Cognitive Decline: A Meta-Analysis of Observational Studies. Neuroepidemiology 47, 171-180, https://doi.org/10.1159/000454737 (2016).

42. Wennberg, A. M. V., Wu, M. N., Rosenberg, P. B. \& Spira, A. P. Sleep Disturbance, Cognitive Decline, and Dementia: A Review. Seminars in neurology 37, 395-406, https://doi.org/10.1055/s-0037-1604351 (2017).

43. Song, Q. et al. Long Sleep Duration and Risk of Ischemic Stroke and Hemorrhagic Stroke: the Kailuan Prospective Study. Scientific reports 6, 33664, https://doi.org/10.1038/srep33664 (2016).

44. Song, Q. et al. Long Sleep Duration Is an Independent Risk Factor for Incident Atrial Fibrillation in a Chinese Population: A Prospective Cohort Study. Scientific reports 7(3679), 8, https://doi.org/10.1038/s41598-017-04034- (2017).

45. Gustavsson, A.-M. et al. Midlife Atherosclerosis and Development of Alzheimer or Vascular Dementia. Annals of neurology https:// doi.org/10.1002/ana.25645 (2019).

46. Rensma, S. P. et al. Microvascular Dysfunction Is Associated With Worse Cognitive Performance: The Maastricht Study. Hypertension (Dallas, Tex.: 1979), HYPERTENSIONAHA11913023; 10.1161/HYPERTENSIONAHA.119.13023 (2019).

47. Baylan, S. et al. Incidence and prevalence of post-stroke insomnia: A systematic review and meta-analysis. Sleep medicine reviews 49 , 101222, https://doi.org/10.1016/j.smrv.2019.101222 (2019).

48. Spiesshoefer, J. et al. Sleep - the yet underappreciated player in cardiovascular diseases: A clinical review from the German Cardiac Society Working Group on Sleep Disordered Breathing. European journal of preventive cardiology, 2047487319879526; https://doi. org/10.1177/2047487319879526 (2019).

49. Kondratova, A. A. \& Kondratov, R. V. The circadian clock and pathology of the ageing brain. Nature reviews. Neuroscience 13 325-335, https://doi.org/10.1038/nrn3208 (2012). 
50. van Egroo, M. et al. Sleep-Wake Regulation and the Hallmarks of the Pathogenesis of Alzheimer's Disease. Sleep; https://doi. org/10.1093/sleep/zsz017 (2019).

51. Ju, Y.-E. S. et al. Sleep quality and preclinical Alzheimer disease. JAMA neurology 70, 587-593, https://doi.org/10.1001/ jamaneurol.2013.2334 (2013).

52. Ju, Y.-E. S., Lucey, B. P. \& Holtzman, D. M. Sleep and Alzheimer disease pathology-a bidirectional relationship. Nature reviews. Neurology 10, 115-119, https://doi.org/10.1038/nrneurol.2013.269 (2014).

53. Naismith, S. L. et al. Circadian misalignment and sleep disruption in mild cognitive impairment. Journal of Alzheimer's disease: JAD 38, 857-866, https://doi.org/10.3233/JAD-131217 (2014).

54. Brown, R. E., Basheer, R., McKenna, J. T., Strecker, R. E. \& McCarley, R. W. Control of sleep and wakefulness. Physiological reviews 92, 1087-1187, https://doi.org/10.1152/physrev.00032.2011 (2012).

55. Coogan, A. N. et al. The circadian system in Alzheimer's disease. Disturbances, mechanisms, and opportunities. Biological psychiatry 74, 333-339, https://doi.org/10.1016/j.biopsych.2012.11.021 (2013).

56. Hayes, T. L., Riley, T., Mattek, N., Pavel, M. \& Kaye, J. A. Sleep habits in mild cognitive impairment. Alzheimer disease and associated disorders 28, 145-150, https://doi.org/10.1097/WAD.0000000000000010 (2014).

57. You, J. C. et al. Association of $\beta$-Amyloid Burden With Sleep Dysfunction and Cognitive Impairment in Elderly Individuals With Cognitive Disorders. JAMA Netw Open 2, e1913383, https://doi.org/10.1001/jamanetworkopen.2019.13383 (2019).

58. Mander, B. A. et al. $\beta$-amyloid disrupts human NREM slow waves and related hippocampus-dependent memory consolidation. Nature Neuroscience 18, 1051-1057, https://doi.org/10.1038/nn.4035 (2015).

59. Roh, J. H. et al. Disruption of the sleep-wake cycle and diurnal fluctuation of $\beta$-amyloid in mice with Alzheimer's disease pathology. Science translational medicine 4, 150ra122, https://doi.org/10.1126/scitranslmed.3004291 (2012).

60. Spira, A. P. et al. Self-reported sleep and $\beta$-amyloid deposition in community-dwelling older adults. JAMA neurology 70, 1537-1543, https://doi.org/10.1001/jamaneurol.2013.4258 (2013).

61. Kang, J.-E. et al. Amyloid-beta dynamics are regulated by orexin and the sleep-wake cycle. Science (New York, N.Y.) 326, 1005-1007, https://doi.org/10.1126/science.1180962 (2009).

62. Vanderheyden, W. M., Lim, M. M., Musiek, E. S. \& Gerstner, J. R. Alzheimer's Disease and Sleep-Wake Disturbances: Amyloid, Astrocytes, and Animal Models. The. Journal of neuroscience: the official journal of the Society for Neuroscience 38, 2901-2910, https://doi.org/10.1523/JNEUROSCI.1135-17.2017 (2018).

63. Fjell, A. M. et al. Self-reported sleep relates to hippocampal atrophy across the adult lifespan - results from the Lifebrain consortium. Sleep; https://doi.org/10.1093/sleep/zsz280 (2019).

64. Yamada, K. et al. Neuronal activity regulates extracellular tau in vivo. The Journal of Experimental Medicine 211, 387-393, https:// doi.org/10.1084/jem.20131685 (2014).

65. Di Meco, A., Joshi, Y. B. \& Praticò, D. Sleep deprivation impairs memory, tau metabolism, and synaptic integrity of a mouse model of Alzheimer's disease with plaques and tangles. Neurobiology of aging 35, 1813-1820, https://doi.org/10.1016/j. neurobiolaging.2014.02.011 (2014).

66. Rothman, S. M., Herdener, N., Frankola, K. A., Mughal, M. R. \& Mattson, M. P. Chronic mild sleep restriction accentuates contextual memory impairments, and accumulations of cortical $\mathrm{A} \beta$ and $\mathrm{pTau}$ in a mouse model of Alzheimer's Disease. Brain research 1529, 200-208, https://doi.org/10.1016/j.brainres.2013.07.010 (2013).

67. Harada, R. et al. 18F-THK5351: A Novel PET Radiotracer for Imaging Neurofibrillary Pathology in Alzheimer Disease. Journal of nuclear medicine: official publication, Society of Nuclear Medicine 57, 208-214, https://doi.org/10.2967/jnumed.115.164848 (2016).

68. Schöll, M. et al. PET Imaging of Tau Deposition in the Aging Human Brain. Neuron 89, 971-982, https://doi.org/10.1016/j. neuron.2016.01.028 (2016).

69. Irwin, M. R., Olmstead, R. \& Carroll, J. E. Sleep Disturbance, Sleep Duration, and Inflammation: A Systematic Review and MetaAnalysis of Cohort Studies and Experimental Sleep Deprivation. Biological psychiatry 80, 40-52, https://doi.org/10.1016/j. biopsych.2015.05.014 (2016).

70. Webers, A., Heneka, M. T. \& Gleeson, P. A. The role of innate immune responses and neuroinflammation in amyloid accumulation and progression of Alzheimer's disease. Immunology and cell biology; https://doi.org/10.1111/imcb.12301 (2019).

71. Musiek, E. S. et al. Circadian Rest-Activity Pattern Changes in Aging and Preclinical Alzheimer Disease. JAMA neurology 75, 582-590, https://doi.org/10.1001/jamaneurol.2017.4719 (2018).

72. Lim, A. S. P. et al. Sleep Modifies the Relation of APOE to the Risk of Alzheimer Disease and Neurofibrillary Tangle Pathology. JAMA neurology 70; https://doi.org/10.1001/jamaneurol.2013.4215 (2013).

73. Medeiros, R., Baglietto-Vargas, D. \& LaFerla, F. M. The role of tau in Alzheimer's disease and related disorders. CNS neuroscience ef therapeutics 17, 514-524, https://doi.org/10.1111/j.1755-5949.2010.00177.x (2011).

74. Stevanovic, K. et al. Disruption of normal circadian clock function in a mouse model of tauopathy. Experimental neurology 294, 58-67, https://doi.org/10.1016/j.expneurol.2017.04.015 (2017).

75. Kowall, B. \& Stang, A. Measurement is always better than self-report: is it that easy? Sleep medicine 38, 157, https://doi.org/10.1016/j. sleep.2017.07.019 (2017).

76. Zinkhan, M. et al. Agreement of different methods for assessing sleep characteristics: a comparison of two actigraphs, wrist and hip placement, and self-report with polysomnography. Sleep medicine 15, 1107-1114, https://doi.org/10.1016/j.sleep.2014.04.015 (2014).

77. Gerards, D. et al. Cognitive Performance of Returners and Non-Returners of a Population-Based Study. Alzheimer's \&. Dementia 14, P529-P530, https://doi.org/10.1016/j.jalz.2018.06.529 (2018).

78. Albert, M. S. et al. The diagnosis of mild cognitive impairment due to Alzheimer's disease: recommendations from the National Institute on Aging-Alzheimer's Association workgroups on diagnostic guidelines for Alzheimer's disease. Alzheimer's \& dementia: the journal of the Alzheimer's Association 7, 270-279, https://doi.org/10.1016/j.jalz.2011.03.008 (2011).

\section{Acknowledgements}

The authors express their gratitude to all study participants of the Heinz Nixdorf Recall (HNR) Study, the personnel of the HNR study center and the EBT-scanner facilities, the investigative group and all former employees of the HNR study. The authors also thank the Advisory Board of the HNR Study: T. Meinertz, Hamburg, Germany (Chair); C. Bode, Freiburg, Germany; P.J. de Feyter, Rotterdam, Netherlands; B. Güntert, Hall i.T., Austria; F. Gutzwiller, Bern, Switzerland; H. Heinen, Bonn, Germany; O. Hess ( $\dagger$ ), Bern, Switzerland; B. Klein $(\dagger)$, Essen, Germany; H. Löwel, Neuherberg, Germany; M. Reiser, Munich, Germany; G. Schmidt ( $\dagger$ ), Essen, Germany; M. Schwaiger, Munich, Germany; C. Steinmüller, Bonn, Germany; T. Theorell, Stockholm, Sweden; and S.N Willich, Berlin, Germany. The authors thank the Heinz Nixdorf Foundation [Chairman: Martin Nixdorf; Past Chairman: Dr jur. Gerhard Schmidt $(\dagger)]$, for their generous support of this study. Parts of the study were also supported by the German Research Council (DFG) [DFG project: EI 969/2-3, ER 155/6-1;6-2, HO 3314/2-1;22;2-3;4-3, INST 58219/32-1, JO 170/8-1, KN 885/3-1, PE 2309/2-1, SI 236/8-1;9-1;10-1,], the German Ministry of Education and Science [BMBF project: 01EG0401, 01GI0856, 01GI0860, 01GS0820_WB2-C, 01ER1001D, 
01GI0205], the Ministry of Innovation, Science, Research and Technology, North Rhine-Westphalia (MIWFTNRW), the Else Kröner-Fresenius-Stiftung [project: 2015_A119] and the German Social Accident Insurance [DGUV project: FF-FP295]. Furthermore the study was supported by the Competence Network for HIV/AIDS, the deanship of the University Hospital and IFORES of the University Duisburg-Essen, the European Union, the German Competence Network Heart Failure, Kulturstiftung Essen, the Protein Research Unit within Europe (PURE), the Dr. Werner-Jackstädt Stiftung and the following companies: Celgene GmbH München, Imatron/ GE-Imatron, Janssen, Merck KG, Philips, ResMed Foundation, Roche Diagnostics, Sarstedt AG\&Co, Siemens HealthCare Diagnostics, Volkswagen Foundation. We acknowledge support by the Open Access Publication Fund of the University of Duisburg-Essen.

\section{Author contributions}

C.B., B.K., A.S., M.J. planned the study; K.J., A.S., S.M., N.D., A.W., S.T., C.W., R.E. and M.J. collected data; C.B. and B.K. did the statistical analyses; C.B. and B.K. wrote the manuscript; all authors reviewed the manuscript

\section{Competing interests}

The authors declare no competing interests.

\section{Additional information}

Supplementary information is available for this paper at https://doi.org/10.1038/s41598-020-63511-9.

Correspondence and requests for materials should be addressed to B.K.

Reprints and permissions information is available at www.nature.com/reprints.

Publisher's note Springer Nature remains neutral with regard to jurisdictional claims in published maps and institutional affiliations.

Open Access This article is licensed under a Creative Commons Attribution 4.0 International License, which permits use, sharing, adaptation, distribution and reproduction in any medium or format, as long as you give appropriate credit to the original author(s) and the source, provide a link to the Creative Commons license, and indicate if changes were made. The images or other third party material in this article are included in the article's Creative Commons license, unless indicated otherwise in a credit line to the material. If material is not included in the article's Creative Commons license and your intended use is not permitted by statutory regulation or exceeds the permitted use, you will need to obtain permission directly from the copyright holder. To view a copy of this license, visit http://creativecommons.org/licenses/by/4.0/.

(c) The Author(s) 2020 